\title{
Vascular Disease and Dementia: Lipoprotein(a) as a Neglected Link
}

\author{
Giuseppe Lippi, MD ${ }^{1}$ Elisa Danese, $\mathrm{PhD}^{1} \quad$ Emmanuel J. Favaloro, PhD, FFSc (RCPA) ${ }^{2}$
}

\author{
1 Section of Clinical Biochemistry, University of Verona, Verona, Italy \\ ${ }^{2}$ Department of Haematology, Institute of Clinical Pathology and \\ Medical Research, NSW Health Pathology, Westmead Hospital, \\ Westmead, New South Wales, Australia
}

Semin Thromb Hemost 2019;45:544-547.

In a recent article published in this issue of the journal, de Mello Gomide Loures et al report their comprehensive review and meta-analysis on the association between hemostatic abnormalities and dementia, ${ }^{1}$ concluding that patients with Alzheimer's disease (AD) display a variety of hemostasis related changes including increased values of von Willebrand factor (VWF), D-dimer, plasminogen activator inhibitor-1, thrombomodulin, and homocysteine. They also report that patients with vascular dementia (VD) show increased values of fibrinogen, activated factor VII, factor VIII, VWF, D-dimer, and homocysteine. These findings lead to the conclusion that hemostasis abnormalities may play an import role in the pathogenesis of dementia. Indeed, these scenarios are entirely plausible, and many hemostasis components evidenced to be raised in $\mathrm{AD}$ and $\mathrm{VD}$, as representing important disorders leading to cognitive decline, are otherwise recognized to represent prothrombotic markers when elevated. ${ }^{2}$

Sometimes, however, it is not what is reported to be linked to a particular disease, but what is missing from such reports that also deserves attention, and thus we also wish to highlight the possible contribution of lipoprotein(a), $\mathrm{Lp}(\mathrm{a})$, to these adverse conditions. $\operatorname{Lp}(\mathrm{a})$ is cholesterolenriched lipoprotein particle, sharing biochemical and structural homology with low-density lipoproteins (LDLs). ${ }^{3}$ Unlike LDL, whose main protein moiety is represented by apolipoprotein B100 (apoB100), Lp(a) also contains apolipoprotein(a), apo(a), which is covalently linked by a disulfide bridge to apoB100. ${ }^{4}$ Apo(a) displays a complicated and repetitive structure, highly homologous to that of human plasminogen, and is characterized by the presence of an inactive protease domain and five other structurally related domains, conventionally called "kringles." Unlike plasminogen, apo(a) contains a unique copy of kringle $\mathrm{V}$ and multiple kringle IV repeats, which are responsible for considerable size heterogeneity of this apolipoprotein and whose number is inversely associated with blood concentration (i.e., the lower the size, the higher the concentration, and vice versa). ${ }^{4}$
Address for correspondence Giuseppe Lippi, MD, Section of Clinical Biochemistry, University Hospital of Verona, Piazzale LA Scuro, 37134 Verona, Italy (e-mail: giuseppe.lippi@univr.it).

The presence of apo(a) confers to $\operatorname{Lp}(\mathrm{a})$ unique and exclusive metabolic features, which may also contribute to make it a potential player in the pathogenesis of dementia.

Reliable epidemiological evidence has been published on the association between $\operatorname{Lp}(\mathrm{a})$ and dementia. The very first study was published by Urakami et al in $1987,{ }^{5}$ in which the authors found that patients with VD had significantly higher Lp(a) levels than age-matched healthy subjects ( $15 \mathrm{vs.} 10 \mathrm{mg}$ / $\mathrm{dL} ; p<0.05)$, whereas $\operatorname{Lp}(\mathrm{a})$ concentration was found to be similar in AD patient and healthy controls (9 vs. $10 \mathrm{mg} / \mathrm{dL}$; $p<0.05$ ).

In an ensuing cross-section study, Kuriyama et al studied 22 patients with senile AD, 29 with VD, and 68 matched healthy controls. ${ }^{6}$ The concentration of $\operatorname{Lp}(a)$ was found to be significantly higher in both patients with VD $(36 \pm 22 \mathrm{mg} /$ $\mathrm{dL})$ and $\mathrm{AD}(33 \pm 30 \mathrm{mg} / \mathrm{dL})$ compared with healthy controls (14 $\pm 4 \mathrm{mg} / \mathrm{dL} ; p<0.001$ for both comparisons). No significant difference was observed between VD and AD cohorts. Unlike these findings, Caramelli failed to find a significant difference of $\mathrm{Lp}(\mathrm{a})$ concentration between 24 patients with $\mathrm{AD}$ and 32 elderly controls $(25 \pm 25$ vs. $26 \pm 18 \mathrm{mg} / \mathrm{dL}$; $p=0.32)^{7}$

Urakami et al measured $\operatorname{Lp}(\mathrm{a})$ in 14 patients with VD, 18 with $A D$, and 47 healthy individuals, ${ }^{8}$ reporting that $\mathrm{Lp}(\mathrm{a})$ values were significantly increased in patients with VD compared with both $\mathrm{AD}$ patients and healthy controls (no final concentration reported; $p<0.05$ for both comparisons). Regarding apo(a) phenotypes, low molecular weight isoforms were more frequent in patients with VD than in healthy individuals.

Mooser et al performed a case-control study including 285 patients with AD and 296 healthy controls, ${ }^{9}$ concluding that $\operatorname{Lp}(a)$ was associated with a reduced risk of $A D$ in noncarriers of the apolipoprotein $\mathrm{E} \boldsymbol{\epsilon} 4$ allele (odds ratio [OR]: 0.4; 95\% confidence interval [CI]: 0.2-0.9), whereas it was associated with an enhanced risk of late-onset $A D$ in those with $\epsilon 4$ allele (OR: 6; 95\% CI: 1.2-30.8). published online May 16, 2019
Issue Theme Editorial Compilation VII; Guest Editors: Emmanuel J. Favaloro, PhD, FFSc (RCPA), and Giuseppe Lippi, MD.
Copyright $\odot 2019$ by Thieme Medical Publishers, Inc., 333 Seventh Avenue, New York, NY 10001, USA. Tel: +1(212) 584-4662.
DOI https://doi.org/ 10.1055/s-0039-1687907. ISSN 0094-6176. 
Zuliani et al measured $\operatorname{Lp}(\mathrm{a})$ in 60 patients with VD, 40 with late onset $\mathrm{AD}$, and 54 nondemented older controls. ${ }^{10}$ The concentration of $\operatorname{Lp}(\mathrm{a})$ was found to be nonsignificantly different across the three cohorts (healthy controls: $21 \mathrm{mg} /$ $\mathrm{dL} ; \mathrm{AD}: 17 \mathrm{mg} / \mathrm{dL}, \mathrm{VD}: 16 \mathrm{mg} / \mathrm{dL} ; p=$ nonsignificant for all comparisons).

Solfrizzi et al performed a cross-sectional study including 61 patients with $\mathrm{AD}$ and 63 healthy age-matched healthy controls, ${ }^{11}$ concluding that $\mathrm{Lp}(\mathrm{a})$ values $>70 \mathrm{mg} / \mathrm{dL}$ were significantly associated with an enhanced risk of AD (OR: 4.7; 95\% CI: 1.6-13.5), independently of sex and apolipoprotein E genotype.

In an ensuing case-control investigation, Emanuele et al measured $\mathrm{Lp}(\mathrm{a})$ in 54 patients with frontotemporal dementia and in 77 matched nondemented controls. ${ }^{12}$ The concentration of $\mathrm{Lp}(\mathrm{a})$ was slightly but nonsignificantly increased in frontotemporal dementia patients compared with healthy controls ( 16 vs. $11 \mathrm{mg} / \mathrm{dL} ; p=0.22$ ). Notably, patients with frontotemporal dementia had a significantly higher frequency of low molecular weight isoforms than the cognitively healthy controls. The same team of authors published another cross-sectional study including 50 patients with VD, 162 with $\mathrm{AD}$, and 105 matched nondemented controls. ${ }^{13}$ The concentration of $\operatorname{Lp}(\mathrm{a})$ was found to be similar in patients with $\mathrm{AD}$ and in the control group (10.6 vs. $7.9 \mathrm{mg} / \mathrm{dL}$; $p=$ nonsignificant), whereas $\operatorname{Lp}(\mathrm{a})$ levels were found to be substantially higher in patients with VD than in the other two cohorts ( $24 \mathrm{mg} / \mathrm{dL} ; p \leq 0.01$ for both comparisons). The frequency of low molecular weight isoforms was significantly higher in VD patients than in the cohorts. The same authors published almost simultaneously another work (73 AD patients compared with 73 matched healthy controls), displaying virtually identical data ( $\operatorname{Lp}(\mathrm{a})$ concentration $11 \mathrm{vs.}$ $12 \mathrm{mg} / \mathrm{dL} ; p=$ nonsignificant), ${ }^{14}$ but emphasizing that AD patients with the null apo(a) allele, which is associated with undetectable levels of $\mathrm{Lp}(\mathrm{a})$, had a delayed onset of $\mathrm{AD}$ compared with those with other apo(a) alleles (i.e., $77 \pm 8$ vs. $67 \pm 10$ years; $p=0.010$ ).

Iwamoto et al studied 150 patients with late-onset $A D, 46$ with VD, and 150 healthy controls, ${ }^{15}$ concluding that Lp(a) values were similar in $\mathrm{AD}$ patients and controls ( $25 \pm 25$ vs. $21 \pm 19 \mathrm{mg} / \mathrm{dL} ; p=$ nonsignificant), whereas Lp(a) concentration was significantly higher in VD patients $(46 \pm 36 \mathrm{mg} / \mathrm{dL}$ ) than in the other two groups ( $p<0.05$ for both comparisons).

Watanabe et al measured Lp(a) in 37 patients with VD, 34 with $\mathrm{AD}$, and 63 healthy controls, ${ }^{16}$ reporting that the concentration of $\mathrm{Lp}(\mathrm{a})$ was slightly but nonsignificantly higher in $\mathrm{AD}$ patients than in the control group $(25 \pm 22 \mathrm{vs} .14 \pm 13 \mathrm{mg} / \mathrm{dL}$; $p=$ nonsignificant), whereas $\operatorname{Lp}(\mathrm{a})$ was substantially higher in patients with VD than in the other two cohorts $(45 \pm 46 \mathrm{mg} / \mathrm{dL}$; $p \leq 0.005$ for both comparisons).

Pantoni et al described the cases of three patients with cerebral autosomal dominant arteriopathy with subcortical infarcts and leukoencephalopathy (CADASIL), ${ }^{17}$ one of whom displayed an extremely elevated value of Lp(a) (i.e., $143 \mathrm{mg} / \mathrm{dL}$; normal reference range: $<30 \mathrm{mg} / \mathrm{dL}$ ).

Cankurtaran studied 120 patients with AD, 55 with VD, and 803 subjects with normal cognitive status. ${ }^{18}$ No signifi- cant differences of $\operatorname{Lp}(\mathrm{a})$ values were found among the three cohorts of patients (normal cognitive status: $25 \pm 18 \mathrm{mg} / \mathrm{dL}$; AD: $25 \pm 12 \mathrm{mg} / \mathrm{dL}$; VD: $29 \pm 35 \mathrm{mg} / \mathrm{dL} ; p=$ nonsignificant for all comparisons).

Ban et al performed a cross-sectional study including 197 with $\mathrm{AD}, 42$ with $\mathrm{VD}$, and 47 healthy controls, ${ }^{19}$ reporting that Lp(a) values were similar between AD patients $(20 \pm 4 \mathrm{mg} / \mathrm{dL})$ and the healthy control group ( $19 \pm 1 \mathrm{mg} / \mathrm{dL} ; p=$ nonsignificant), whereas its concentration was substantially higher in patients with VD than in the other two groups $(32 \pm 4 \mathrm{mg} / \mathrm{dL}$; $p<0.001$ for both comparisons).

In another report, Gong et al described the case of a family with CADASIL and increased values of $\operatorname{Lp}(a) .{ }^{20}$ Similar findings were then reported by Valenti et al, ${ }^{21}$ who also studied three families with CADASIL and reported that the affected members displayed extremely high concentration of $\operatorname{Lp}(a)$, comprised between 32 and $143 \mathrm{mg} / \mathrm{dL}$.

More recently, Ray et al performed a cross-sectional study including 40 patients with $\mathrm{AD}, 40$ with $\mathrm{VD}$, and 40 agematched healthy controls. ${ }^{22}$ Interestingly, although the concentration of $\operatorname{Lp}(\mathrm{a})$ was found to be virtually identical in patients with $\mathrm{AD}$ and in the control group (both $\sim 25 \mathrm{mg} / \mathrm{dL}$ ), $\mathrm{Lp}$ (a) levels were found to be nearly twice higher in patients with VD $(\sim 50 \mathrm{mg} / \mathrm{dL})$ than in the other two cohorts ( $p<0.001$ for both comparisons).

The only prospective study on the relationship between $\mathrm{Lp}(\mathrm{a})$ and dementia was published by Kunutsor et al in 2016. ${ }^{23}$ Briefly, the authors measured Lp(a) concentration at baseline in 2,532 men aged between 42 and 61 years, who were then followed up for a median period of 24.9 years. Overall, 228 incident cases of dementia were recorded. In age-adjusted analysis, $\mathrm{LP}(\mathrm{a})$ was found to be inversely associated with the risk of incident dementia (hazard ratio: 0.68; 95\% CI: 0.46-0.99).

Taken together, these findings would suggest that although the link between $\mathrm{Lp}(\mathrm{a})$, impaired cognitive performance, and $\mathrm{AD}$ remains elusive, ${ }^{24}$ it cannot be discounted that in the vast majority of published studies, $\operatorname{Lp}(\mathrm{a})$ concentration was found to be higher in subjects with VD or CADASIL than in those with normal cognitive status (-Table 1). Therefore, this lipoprotein seems to play a certain role in the pathogenesis of VD and to be supported by at least four plausible biological mechanisms (i.e., enhanced atherogenesis, endothelial dysfunction, impaired fibrinolysis, and platelet hyperactivation) ( - Fig. 1), which are also strongly involved in the pathogenesis of dementia, especially in that of the vascular form (i.e., VD). ${ }^{25}$

Atherogenesis is indeed the most historically known pathological effect of $\operatorname{Lp}(\mathrm{a})$. $\operatorname{Lp}(\mathrm{a})$ contains a large amount of cholesterol and is known to amplify the atherogenic process in blood vessels through many different mechanisms (comprehensively reviewed elsewhere). ${ }^{26}$ On the other hand, atherosclerosis is also commonplace in patients with $\mathrm{AD}$ and, especially, VD. ${ }^{25}$

Endothelial dysfunction is a second putative mechanism possibly linking Lp(a) with (vascular) dementia. Reliable evidence has been published that an increased value of LP (a) is strongly associated with endothelial dysfunction, 
Table 1 Summary of epidemiological evidence on $L p(a)$ levels in patients with dementia

\begin{tabular}{|c|c|c|}
\hline Authors & Study & Results \\
\hline Urakami K et al, $1987^{5}$ & Cross-sectional & Lp(a) higher in VD patients than in AD patients and healthy controls \\
\hline Kuriyama et al, $1992^{6}$ & Cross-sectional & Lp(a) higher in patients with AD and VD than in healthy controls \\
\hline Caramelli et al, $1999^{7}$ & Cross-sectional & Lp(a) similar in AD patients and healthy controls \\
\hline Urakami et al, $2000^{8}$ & Cross-sectional & Lp(a) higher in VD patients than in AD patients and healthy controls \\
\hline Mooser et al, $2000^{9}$ & Cross-sectional & $\begin{array}{l}\text { Lp(a) associated with } A D \text { in carriers of apolipoprotein } E \epsilon 4 \text { allele } \\
\text { but not in those without }\end{array}$ \\
\hline Zuliani et al, $2001^{10}$ & Cross-sectional & Lp(a) similar in patients with VD, AD, and healthy controls \\
\hline Solfrizzi et al, $2002^{11}$ & Cross-sectional & High values of $L p(a)$ associated with an enhanced risk of $A D$ \\
\hline Emanuele et al, $2003^{12}$ & Cross-sectional & Lp(a) similar in patients with frontotemporal dementia and healthy controls \\
\hline Emanuele et al, $2004^{13}$ & Cross-sectional & Lp(a) higher in VD patients than in AD patients and healthy controls \\
\hline Emanuele et al, $2004^{14}$ & Cross-sectional & Lp(a) similar in patients with AD and healthy controls \\
\hline Iwamoto et al, $2004^{15}$ & Cross-sectional & Lp(a) higher in VD patients than in AD patients and healthy controls \\
\hline Watanabe et al, $2004^{16}$ & Cross-sectional & Lp(a) higher in VD patients than in AD patients and healthy controls \\
\hline Pantoni et al, $2004^{17}$ & Case report & High Lp(a) value in a patient with CADASIL \\
\hline Cankurtaran et al, $2005^{18}$ & Case report & Lp(a) similar in patients with AD or VD and healthy controls \\
\hline Ban et al, $2009^{19}$ & Cross-sectional & Lp(a) higher in VD patients than in AD patients and healthy controls \\
\hline Gong et al, $2010^{20}$ & Case report & High Lp(a) values in a family with CADASIL \\
\hline Valenti et al, $2012^{21}$ & Case report & High Lp(a) values in three families with CADASIL \\
\hline Ray et al, $2013^{22}$ & Cross-sectional & Lp(a) higher in VD patients than in AD patients and healthy controls \\
\hline Kunutsor et al, $2016^{23}$ & Perspective & Lp(a) inversely associated with the risk of incident dementia \\
\hline
\end{tabular}

Abbreviations: AD, Alzheimer's disease; CADASIL, cerebral autosomal dominant arteriopathy with subcortical infarcts and leukoencephalopathy; Lp (a), lipoprotein(a); VD, vascular dementia.

proliferation, and migration of smooth muscle cells, ${ }^{27}$ which are also key events in the pathogenesis of both AD and VD. ${ }^{28}$

Besides its well-established atherogenic properties, Lp(a) seems to play a role also in the pathogenesis of venous thrombosis. ${ }^{29}$ This is probably attributable to its antifibrinolytic properties, because the high structural homology between apo (a) and plasminogen leads both proteins to compete for binding to fibrin and cell membrane. ${ }^{30}$ Therefore, in patients with high Lp(a) values, plasminogen binding to its receptors is partially disrupted, and fibrinolyis would be finally impaired.

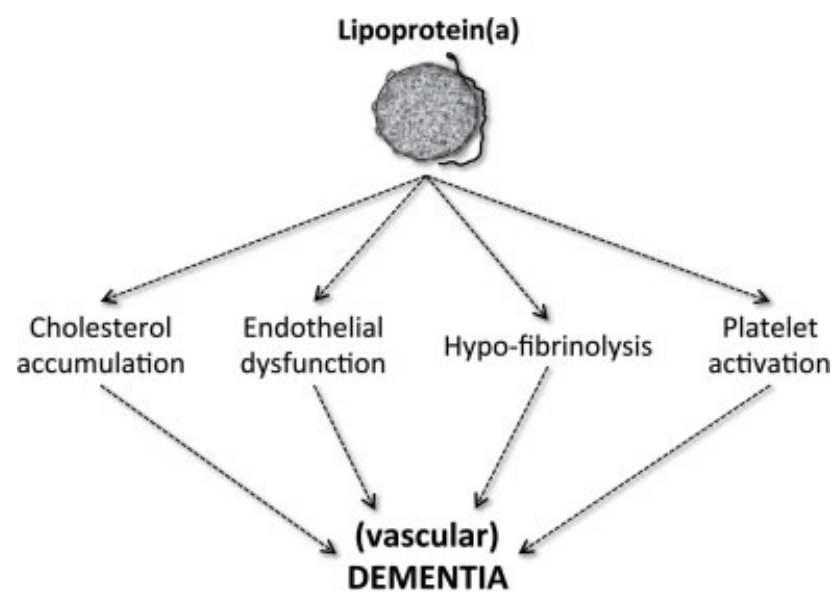

Fig. 1 Potential links between lipoprotein(a) and cognitive decline.
Platelet hyperactivation is another important aspect in the pathogenesis of dementia and $\mathrm{AD},{ }^{31}$ whereas it has been demonstrated that both $\operatorname{Lp}(\mathrm{a})$ and $\mathrm{apo}(\mathrm{a})$ are capable to enhance platelet activation and aggregation. ${ }^{27}$

While it seems therefore plausible to conclude that $\operatorname{Lp}(\mathrm{a})$ may be both epidemiologically and biologically associated with (vascular) dementia and that $\mathrm{Lp}(\mathrm{a})$ may effectively interplay with other well-known risk factors of dementia such as hyperhomocysteinemia or apolipoprotein $\mathrm{E} \boldsymbol{\epsilon} 4$ allele, reliable evidence has also been published that this lipoprotein may be actively participating in cognitive decline. Takechi et al showed apoB colocalization with amyloid $\beta$ (A $\beta$ ) within dense neuritic amyloid plaque, which are hallmarks of dementia. ${ }^{32}$ Leung et al also performed a large study including 344 patients with AD and 325 cognitively normal subjects from whom cerebrospinal fluid (CSF) samples were collected and analyzed. ${ }^{33}$ Overall, $L p(a)$ and $A \beta_{1-42}$ levels in CSF were found to be significantly associated ( $p=0.012)$.

In conclusion, several lines of evidence would lead us to conclude that the role of increased $\mathrm{Lp}$ (a) values should not be neglected in dementia, especially in those forms with predominantly vascular nature. This aspect is especially important considering that high values of $\mathrm{Lp}(\mathrm{a})$ are compatible with longevity, ${ }^{34}$ thus potentially exposing many elderly people to an increased risk of developing some forms of cognitive impairment. Nevertheless, this correspondence is not meant as a criticism of the review and meta-analysis 
prepared by de Mello Gomide Loures et al. ${ }^{1}$ Why Lp(a) was not identified as a putative marker associated with (vascular) dementia most likely simply relates to their search limitations and their focus on "hemostatic factors." Although Lp(a) shares some structural homology to plasminogen, a precursor of plasmin, and thus involved in fibrinolysis and linked to hemostasis, it is not really considered to be a hemostasisrelated protein. Thus, the findings reported by de Mello Gomide Loures et al, focused on hemostasis, should not be considered as definitive in terms of vascular markers associated with dementia. Moreover, although it is unlikely that their report covers only the tip of an iceberg, it is likely that their report represents but a sampling of the potential involvement of hemostasis and vascular-associated proteins in conditions that present with considerable clinical adversity-namely, dementia and cognitive decline-and especially as related to any vascular contributors.

\section{Conflicts of Interest}

None.

\section{References}

1 de Mello Gomide Loures C, Figueiredo Duarte RC, Ferreira Silva MV, et al. Hemostatic abnormalities in dementia: a systematic review and meta-analysis. Semin Thromb Hemost 2019;45(05): 514-522

2 Montagnana M, Lippi G, Danese E. An overview of thrombophilia and associated laboratory testing. Methods Mol Biol 2017; 1646:113-135

3 Lippi G, Guidi G. Lipoprotein(a): from ancestral benefit to modern pathogen? QJM 2000;93(02):75-84

4 Lippi G, Franchini M, Salvagno GL, Guidi GC. Lipoprotein[a] and cancer: anti-neoplastic effect besides its cardiovascular potency. Cancer Treat Rev 2007;33(05):427-436

5 Urakami K, Mura T, Takahashi K. Lp(a) lipoprotein in cerebrovascular disease and dementia. Jpn J Psychiatry Neurol 1987;41(04): 743-748

6 Kuriyama M, Hokezu Y, Togo S, et al. Serum lipids, lipoproteins and apolipoproteins in patients with senile dementia [in Japanese]. Nippon Ronen Igakkai Zasshi 1992;29(7-8):559-564

7 Caramelli P, Nitrini R, Maranhão R, et al. Increased apolipoprotein B serum concentration in Alzheimer's disease. Acta Neurol Scand 1999;100(01):61-63

8 Urakami K, Wada-Isoe K, Wakutani Y, et al. Lipoprotein(a) phenotypes in patients with vascular dementia. Dement Geriatr Cogn Disord 2000;11(03):135-138

9 Mooser V, Helbecque N, Miklossy J, Marcovina SM, Nicod P, Amouyel P. Interactions between apolipoprotein E and apolipoprotein(a) in patients with late-onset Alzheimer disease. Ann Intern Med 2000;132(07):533-537

10 Zuliani G, Ble' A, Zanca R, et al. Lipoprotein profile in older patients with vascular dementia and Alzheimer's disease. BMC Geriatr 2001; $1: 5$

11 Solfrizzi V, Panza F, D'Introno A, et al. Lipoprotein(a), apolipoprotein E genotype, and risk of Alzheimer's disease. J Neurol Neurosurg Psychiatry 2002;72(06):732-736

12 Emanuele E, Peros E, Tomaino C, et al. Association between small apolipoprotein(a) isoforms and frontotemporal dementia in humans. Neurosci Lett 2003;353(03):201-204
13 Emanuele E, Peros E, Tomaino C, et al. Relation of apolipoprotein (a) size to Alzheimer's disease and vascular dementia. Dement Geriatr Cogn Disord 2004;18(02):189-196

14 Emanuele E, Peros E, Tomaino C, et al. Apolipoprotein(a) null phenotype is related to a delayed age at onset of Alzheimer's disease. Neurosci Lett 2004;357(01):45-48

15 Iwamoto T, Watanabe D, Umahara T, et al. Dual inverse effects of lipoprotein(a) on the dementia process in Japanese late-onset Alzheimer's disease. Psychogeriatrics 2004;4(06):64-71

16 Watanabe T, Koba S, Kawamura M, et al. Small dense low-density lipoprotein and carotid atherosclerosis in relation to vascular dementia. Metabolism 2004;53(04):476-482

17 Pantoni L, Sarti C, Pescini F, et al. Thrombophilic risk factors and unusual clinical features in three Italian CADASIL patients. Eur J Neurol 2004;11(11):782-787

18 Cankurtaran M, Yavuz BB, Halil M, Dagli N, Cankurtaran ES, Ariogul S. Are serum lipid and lipoprotein levels related to dementia? Arch Gerontol Geriatr 2005;41(01):31-39

19 Ban Y, Watanabe T, Suguro T, et al. Increased plasma urotensin-II and carotid atherosclerosis are associated with vascular dementia. J Atheroscler Thromb 2009;16(03):179-187

20 Gong M, Rueschendorf F, Marx P, et al. Clinical and genetic features in a family with CADASIL and high lipoprotein (a) values. J Neurol 2010;257(08):1240-1245

21 Valenti R, Nannucci S, Pescini F, Bianchi S, Inzitari D, Pantoni L. High lipoprotein(a) serum levels in three CADASIL families. J Neurol 2012;259(02):379-380

22 Ray L, Khemka VK, Behera P, et al. Serum homocysteine, dehydroepiandrosterone sulphate and lipoprotein (a) in Alzheimer's disease and vascular dementia. Aging Dis 2013;4(02):57-64

23 Kunutsor SK, Khan H, Nyyssönen K, Laukkanen JA. Is lipoprotein (a) protective of dementia? Eur J Epidemiol 2016;31(11):1149-1152

24 Sarti C, Pantoni L, Pracucci G, Di Carlo A, Vanni P, Inzitari D; Italian Longitudinal Study on Aging (ILSA). Lipoprotein(a) and cognitive performances in an elderly white population: cross-sectional and follow-up data. Stroke 2001;32(07):1678-1683

25 Iemolo F, Duro G, Rizzo C, Castiglia L, Hachinski V, Caruso C. Pathophysiology of vascular dementia. Immun Ageing 2009;6:13

26 Kotani K, Serban MC, Penson P, Lippi G, Banach M. Evidence-based assessment of lipoprotein(a) as a risk biomarker for cardiovascular diseases - Some answers and still many questions. Crit Rev Clin Lab Sci 2016;53(06):370-378

27 Riches K, Porter KE. Lipoprotein(a): cellular effects and molecular mechanisms. Cholesterol 2012;2012:923289

28 Zuliani G, Cavalieri M, Galvani M, et al. Markers of endothelial dysfunction in older subjects with late onset Alzheimer's disease or vascular dementia. J Neurol Sci 2008;272(1-2):164-170

29 Dentali F, Gessi V, Marcucci R, Gianni M, Grandi AM, Franchini M. Lipoprotein(a) as a risk factor for venous thromboembolism: a systematic review and meta-analysis of the literature. Semin Thromb Hemost 2017;43(06):614-620

30 Anglés-Cano E, de la Peña Díaz A, Loyau S. Inhibition of fibrinolysis by lipoprotein(a). Ann N Y Acad Sci 2001;936:261-275

31 Sevush S, Jy W, Horstman LL, Mao WW, Kolodny L, Ahn YS. Platelet activation in Alzheimer disease. Arch Neurol 1998;55(04):530-536

32 Takechi R, Galloway S, Pallebage-Gamarallage M, Wellington C, Johnsen R, Mamo JC. Three-dimensional colocalization analysis of plasma-derived apolipoprotein B with amyloid plaques in APP/ PS1 transgenic mice. Histochem Cell Biol 2009;131(05):661-666

33 Leung YY, Toledo JB, Nefedov A, et al. Identifying amyloid pathologyrelated cerebrospinal fluid biomarkers for Alzheimer's disease in a multicohort study. Alzheimers Dement (Amst) 2015;1(03):339-348

34 Lippi G, Targher G, Salvagno GL, Montagnana M, Franchini M, Guidi GC. Lipoprotein(a) and ageing. Clin Lab 2010;56(9-10):463-466 